\title{
EL USO LEGÍTIMO DE LA FUERZA POLICIAL: BREVE ACERCAMIENTO AL CONTEXTO MEXICANO
}

\author{
Legitimate use of the policial force: brief approach to mexican context
}

\author{
Luis Felipe Guerrero Agripino \\ Adriana de Santiago Álvarez ${ }^{2}$
}

\begin{abstract}
Sumario:
I. Introducción. II. Punto de partida: La justificación del actuar policial desde el ámbito jurídico penal. II.1. Tratamiento desde la antijuridicidad (el cumplimiento de un deber). III. Seguridad pública y la función policial en el contexto de un Estado de Derecho. III.1. Origen de la facultad del Estado para usar la fuerza. III.2 Alcances del término seguridad pública. III.3 Función policial. III.3.1. El uso de la fuerza. III.3.2. El papel de la policía en un Estado democrático de Derecho. IV. Actuación policial y derechos humanos. IV.1. El actuar del policía. IV.2. Apreciación fenomenológica del actuar policial. IV.2.1. Los cuerpos policiales. IV.2.2. El acto de autoridad. IV.4. Trascendencia del respeto a los derechos humanos en la actuación policial. V. Generalidades sobre el uso de la fuerza policial. V.1. Comentario inicial. V.2. Concepto. V.3. Dificultad e importancia de la definición. V.4. Uso excesivo de la fuerza policial. VI. Principios a los que debe sujetarse el uso de la fuerza policial. VI.1. Principios fundamentales. VI.2 Directrices complementarias. VII. Régimen jurídico del uso de la fuerza. VII.1. Orden jurídico nacional. VII.2. Orden jurídico internacional. VIII. Algunas opciones de abordaje a la problemática planteada. VIII.1. Comentario inicial. VIII.2. Marco regulatorio específico. VIII.3. Implementación y operación del servicio profesional de la carrera policial. VIII.3.1. Reclutamiento y selección. VIII.3.2. Profesionalización. IX. Última consideración: la importancia del capital social del policía. X. Bibliografía.
\end{abstract}

Resumen: En la actualidad, existe la percepción de que los casos de uso excesivo de la fuerza policial, se han convertido en un grave problema socio-institucional que es impostergable atender. Para ello, es importante tener precisión de su marco de referencia en el contexto del estado de derecho, a fin de visualizar distintas opciones viables de regulación y tratamiento en el contexto mexicano.

Palabras clave: Estado de derecho, seguridad pública, función policial, actuación policial, violencia, fuerza policial, derechos humanos, marco regulatorio, servicio profesional, controles, teoría del delito.

Abstract: Today, there is a perception that cases of excessive use of police force have become a serious social and institutional problem that is urgent to address. For this reason, it is important

\footnotetext{
${ }^{1}$ Doctor en Derecho Por la Universidad de Salamanca, España. Profesor titular del Departamneto de Derecho de la División de Derecho, Política y Gobierno de la Universidad de Guanajuato. Rector del Campus Guanjuato, Universidad de Guanajuato.

${ }^{2}$ Maestra en Ciencias Jurídico-Penales por la Universidad de Guanajuato, México. Consultora de marzo 2012 al 31 de enero de 2013. Fungió como Directora General de Apoyo Técnico del Secretariado Ejecutivo del Sistema Estatal de Seguridad Pública del Estado de Guanajuato, México.
} 
to have accuracy of their frame of reference in the context of the rule of law, in order to visualize different viable options for regulation and treatment in the Mexican context.

Keywords: Rule of law, public safety, policing function, police action, violence, policing force, human rights, regulatory framework, professional service, controls, theory of crime.

\section{INTRODUCCIÓN}

Dos escenarios extremos que preocupan a la sociedad y debilitan el orden estatal: Por un lado, la omisión o débil actuación de los cuerpos policiales ante la probable comisión de hechos delictivos o faltas administrativas; por otro lado, el excesivo, y a veces brutal uso de la fuerza policial ante comportamientos individuales o reacciones sociales que, aunque si bien pudiesen llegar a constituir conductas ilícitas, la reacción institucional es desmedida. Ambos escenarios son lamentables, por la impunidad que se genera o por la violencia institucional que se produce.

¿Qué hacer ante este tipo de cuestionamientos que paralizan o corrompen la actuación policial? O mejor dicho: ¿Cómo hacerlo, desde la perspectiva de los cuerpos policiales? ¿Cuándo y cómo actuar? Estas interrogantes se deben responder, en nuestro contexto, a la luz de un Estado social y democrático de derecho, en el que el Estado posee la potestad del uso legítimo de la fuerza, pero no la tiene de manera ilimitada. Por lo tanto, debe encontrarse el equilibrio deseable, deben configurarse los baremos idóneos que le permitan legitimar su actuación en cuanto garante del orden, más no como incitador del pánico colectivo.

No existen fórmulas mágicas para encontrar ese marco de actuación, pero sí la posibilidad de construir derroteros idóneos. Precisamente en esa posibilidad se encuadra el objeto de estudio de este trabajo. Antes, queremos establecer algunas delimitaciones.

Es importante señalar que el presente trabajo no contiene una revisión pormenorizada o una nueva visión de las implicaciones del inadecuado uso de la fuerza por parte de los cuerpos de seguridad pública en un Estado democrático de derecho; tampoco intentará mostrar un panorama completo y detallado sobre el empleo de la fuerza estatal en México. Nuestro objetivo es más modesto. Consiste, en términos generales, en presentar un breve marco de referencia sobre el uso legítimo de la fuerza policial y las propuestas normativasinstitucionales para abordarlo o regularlo, con intención de facilitar la comprensión de las implicaciones que conlleva, y de las alternativas que hemos identificado como viables para abordar de manera eficaz este fenómeno estructural de nuestra sociedad y de sus organizaciones públicas.

A fin de abordar de inmediato nuestro tema central, asumimos algunos conceptos fundamentales sin entrar en mayor análisis (V.gr. el marco conceptual del Estado democrático y de derecho), o bien, tomamos como referente de la investigación algunas percepciones que se palpan del sentir de la sociedad mexicana (V.gr. La existencia de un problema socioinstitucional vinculado con el uso indebido de la prerrogativa del uso de la fuerza, por parte de la fuerzas de seguridad pública).

Un signo distintivo de las sociedades contemporáneas -junto con el fenómeno de la globalización y las tecnologías de la información y la comunicación- es la violencia. Ésta adquiere 
rasgos no sólo de omnipresencia ${ }^{3}$ sino también de incremento en su frecuencia e intensidad, ${ }^{4}$ lo cual ha generado en contrapartida que el uso de la fuerza estatal adquiera trascendencia. Piénsese, por ejemplo, en el debate sobre la actuación de los cuerpos policiales, el ejército y la marina en la estrategia de lucha contra el crimen organizado5, las discusiones académicas6, recientes leyes locales, ${ }^{7}$ reglamentos, ${ }^{8}$ iniciativas de ley federales ${ }^{9}$ sobre la implicaciones de uso de la fuerza por parte del Estado, y, particularmente, la reforma a la Constitución Política de los Estados Unidos Mexicanos -En lo sucesivo CPEUM- del 18 de junio de 2008 en materia de seguridad pública que establece como un eje fundamental la necesidad de formación y profesionalización de la función policial como sustento del nuevo modelo policial planteado por dicha reforma. En fin, resulta indispensable una propuesta para abordar y regular este problema socio-institucional.

${ }^{3}$ Al encontrarla en todas las relaciones humanas y los espacios sociales: En la amistad, en la pareja, en la familia, en la escuela, en el trabajo, en la comunidad y en la sociedad; también entre factores reales de poder, entre empresas, entre grupos de interés, entre Estado y ciudadanos, entre Estado y probables delincuentes, entre organizaciones criminales, entre personas privadas de su libertad o entre países, por ejemplo.

4 Conceptos como conflicto, violencia, y el derecho a vivir en paz, pueden verse en De Santiago Alvarez, Adriana, Algunos apuntes a la construcción de la cultura de la paz como eje transversal de la vida social y de las políticas públicas del Estado de Guanajuato, ensayo presentado para acreditar el Diplomado de Medios Alternativos de Solución de Conflictos, Poder Judicial del Estado de Guanajuato, México, mayo-agosto de 2011, pp. 1-3.

5 En México, la estrategia del anterior ejecutivo federal (2006-2012) para debilitar y luchar contra el narcotráfico y el crimen organizado generó un intenso debate en esferas sociales y políticas. En efecto, la denominada "guerra contra el narcotráfico" (con este término denominaron los medios de comunicación, en México, a la estrategia y operativos puestos en marcha por el gobierno del ex-Presidente Felipe Calderón Hinojosa y llevados a cabo por la policía federal, el ejército y la marina para reprimir a los cárteles mexicanos que trafican drogas.), por una parte, pareciera no ser efectiva para imponer el orden, proporcionar la seguridad, restablecer la paz y la tranquilidad que exige la sociedad; y, más aún, se ha afectado a la población civil -como supuestos "daños colaterales" (de esta manera denominó el ex- Secretario de la Defensa Nacional, Guillermo Galván Galván, a la muerte de civiles en el marco de la guerra contra el narcotráfico al comparecer ante legisladores indicando: "A pesar de las muertes de civiles en los enfrentamientos entre las fuerzas armadas y el crimen organizado, la estrategia se mantendrá, son daños colaterales que son lamentables". Periódico La Jornada, martes 13 de abril de 2010, p. 5)-, poniendo de manifiesto carencias en el sistema de seguridad pública, corrupción, así como falta de profesionalización de policías y militares quienes frecuentemente vulneran los derechos humanos abusando de sus facultades. Sobre este tema de interés actual en el contexto nacional, Vid. Guerrero Agripino, Luis Felipe, La delincuencia organizada. Algunos aspectos penales, criminológicos político-criminales, Universidad de Guanajuato, Facultad de Derecho, México, 20o1; también, "Delincuencia organizada: una amenaza emergente para el Estado mexicano", en: Letras Jurídicas, número 12, España, 2011.

${ }^{6}$ Este debate actual confluye con otras discusiones académicas e institucionales sobre el uso legítimo de la fuerza por parte de los cuerpos policiales. El Instituto para la Seguridad y la Democracia, A.C. organizó el 30 de noviembre de 2006, una interesante y significativa mesa debate denominada "Policía y uso de la fuerza, una agenda clave de nuestra democracia", en la que participaron policías, académicos, periodistas, comisionados de derechos humanos y la sociedad civil para discutir la cuestión. También, bajo los auspicios del Instituto Nacional de Ciencias Penales se organizó el Congreso internacional uso de la fuerza pública en un Estado democrático de derecho el 18 de agosto de 2010.

7 El 22 de abril de 2008 fue publicada en la Gaceta Oficial del Distrito Federal la Ley que regula el uso de la fuerza de los cuerpos de seguridad pública del Distrito Federal. Es el único cuerpo normativo de esta naturaleza existente en México.

${ }^{8}$ Reglamento de la Ley que Regula el Uso de la Fuerza de los Cuerpos de Seguridad Pública del Distrito Federal, publicado el 25 de noviembre de 2010 en la Gaceta Oficial del Distrito Federal.

9 El 17 de septiembre de 2008, el Senador René Arce Islas, sometió a consideración del Senado de la República el Proyecto de decreto que crea la Ley General de Procedimientos Policiales y Uso Legítimo de la Fuerza Públi$c a$, iniciativa que no ha prosperado. 
Así, centraremos nuestra atención en la violencia institucionalizada que se genera entre el Estado y los gobernados y, específicamente, al uso de la fuerza ejercida por los cuerpos de seguridad pública, no por el ejército, tema con relevancia y complejidades propias que merece un estudio independiente.

El tema de estudio (uso de la fuerza policial frente a probables delincuentes o infractores), a su vez, admite dos supuestos. El primero, se encuentra referido a aquellos probables delincuentes de delitos comunes. El segundo supuesto se ubica en lo que se ha llamado delincuencia organizada, que en la actualidad en México ha adquirido rasgos fenomenológi$\cos ^{10}$ de suyo peculiares, identificados sobre todo por la violencia creciente, multidireccional y exacerbada que, a su vez, ha propiciado la creación de un régimen jurídico y prácticas operativas de excepción. Es decir, el uso de la fuerza policial en contra de este tipo de delincuencia, adquiere notas específicas que también escapan al alcance de este trabajo. Es decir, lo que a lo largo de aquí señalaremos, se refiere a aquel uso de la fuerza policial aplicado a la "delincuencia común".

Así pues, establecidas las delimitaciones y alcances de este trabajo, nuestra principal pretensión se orienta en dos sentidos: describir un panorama general de la situación actual del tema y ofrecer un enfoque sintético de su tratamiento normativo-institucional. Es decir, el encuadre del objeto de estudio en el marco de la política criminal estatal acorde al modelo democrático que debe derivarse en nuestro país.

\section{PUNTO DE PARTIDA: LA JUSTIFICACIÓN DEL ACTUAR POLICIAL DESDE EL ÁMBITO JURÍDICO PENAL}

Cuando hablamos de los alcances y límites del actuar policial, generalmente se nos vienen a la mente las repercusiones jurídico-penales. Es decir, nos preguntamos cuándo y cómo pueden actuar los elementos policiales sin que su hecho sea delictivo. Desde luego dicha interrogante no debe resultarle ajena al propio agente policial pues de ello depende no solo realizar bien su trabajo sino también su situación personal.

El tratamiento de esos supuestos se encuentra, principalmente, en el ámbito del Derecho penal. Desde esa perspectiva, lo primero que debemos ubicar es su análisis desde la sistemática del delito a fin de precisar los alcances del actuar policía en el contexto nuestro estudio.

Sabemos que para que se actualice un delito se requiere la concurrencia de una serie de elementos. Si falta alguno, el delito no se realiza. En contrapartida, existen instituciones jurídico-penales que precisamente, de presentarse, eliminan el elemento respectivo. A continuación nos enfocaremos en los principales elementos en los que tiene injerencia la actuación policial al momento de hacer uso de la fuerza.

\section{II.1. TRATAMIENTO DESDE LA ANTIJURIDICIDAD (EL CUMPLIMIENTO DE UN DEBER)}

Resulta preciso tener en cuenta lo que en esencia es la antijuridicidad: "equivale a la contradicción del ordenamiento jurídico en general. Es el desvalor del acto y del resultado en un contexto valorativo integral en el cual se encuentra inmerso el sistema jurídico. Para establecer cuándo un determinado comportamiento es antijurídico se necesita hacer una ponderación de intereses, en aras de propiciar la aplicación de un Derecho penal racional

\footnotetext{
${ }^{10}$ Vid. Guerrero Agripino, Luis Felipe. "Panorama general de la criminalidad grupal en México. Desarrollo de la delincuencia organizada y otras manifestaciones de alto impacto”, en: Iustel, número 15, España, 2011. 
(...) En otras palabras, todo comportamiento típico será antijurídico siempre que no exista una causa de justificación". ${ }^{11}$

La doctrina, generalmente, reconoce como causas de justificación que eliminan la antijuridicidad: la legítima defensa, el estado de necesidad, el cumplimiento de un deber y el ejercicio de un derecho.

Para el caso que nos ocupa, es menester situarnos en una específica causa de justificación: el cumplimiento de un deber. A manera de ejemplo, nos ubicaremos en la fracción V del artículo el 15 del Código Penal Federal, el cual regula una cláusula representativa de esta figura. De dicha fracción se desprende que el cumplimiento de un deber se actualiza siempre que en la realización del actuar exista la necesidad racional del medio empleado. ${ }^{12}$

Nótese la trascendencia del alcance de la regulación: la racionalidad de los medios que emplea el agente policial. Al respecto surgen grandes interrogantes: ¿Cuándo un acto policial es racional o cuándo deja de serlo? Esos criterios no se encuentran en los códigos Penales. Es necesario derivarlos desde una perspectiva meta penal. Precisamente de ello hablaremos en las siguientes líneas.

III. SEGURIDAD PÚBLICA Y LA FUNCIÓN POLICIAL EN EL CONTEXTO DE UN ESTADO DE DERECHO

\section{1. ORIGEN DE LA FACULTAD DEL ESTADO PARA USAR LA FUERZA}

La facultad estatal para emplear la fuerza tiene su origen con el mismo nacimiento del Estado; de hecho es su fundamento, su razón primigenia de ser. Se ubica en la transición de la venganza privada a la venganza pública: que no sean los particulares quienes resuelvan sus diferencias por propia mano y bajo sus propias reglas, sino que sea una entidad distinta la que resuelva dichas controversias, aun empleando la fuerza.

El Estado se forma cuando un conglomerado social requiere protegerse. Para lograrlo, se les otorga a algunos miembros de este Estado la facultad y obligación de usar la fuerza para mantener las condiciones de protección necesarias para el desarrollo de la sociedad. ${ }^{13}$ Pero la vigencia de esta facultad estatal está íntimamente ligada a un concepto fundamental de las

\footnotetext{
${ }^{11}$ Guerrero Agripino, Luis Felipe, Teoría del delito y argumentación jurídica. (Notas para la construcción de la teoría del caso en el sistema acusatorio), coedición a cargo de la Procuraduría General de Justicia del Estado de Guanajuato, Poder Judicial del Estado de Guanajuato, LXI Legislatura del Estado de Guanajuato y Universidad de Guanajuato, México, 2011, p. 63.

${ }^{12}$ También escapan de este trabajo, aspectos sistemáticos que generalmente aborda la doctrina al referir la actuación policial desde la perspectiva de la teoría del delito: cuando el agente obedece una orden notoriamente antijurídica, cuando es ilegítima, pero lo desconoce o cuando conociendo tal situación actúa por coacción. Tales casos se resuelven, en la culpabilidad, particularmente desde el tratamiento en el error de prohibición o de la no exigibilidad de otra conducta diversa, respectivamente. Al respecto, vid. Plascencia Villanueva, Raúl, "Uso se la fuerza pública y cumplimiento del deber. La justificación del ejercicio de la coacción pública en el Derecho penal mexicano”, en: Academia Mexicana de Ciencias Penales, año LXXIV, No. 1, México, D.F., enero-abril, 2008, pp. 79 y ss.

${ }^{13}$ Vid. Instituto para la Seguridad y la Democracia, A.C. (INSYDE), Policía y uso de la fuerza, una agenda clave de nuestra democracia, Cuaderno de Trabajo No. 16, 30 de noviembre de 2006, p. 8.
} 
sociedades modernas: el Estado de Derecho, ${ }^{14}$ que se refiere al Estado cuyo poder y actividad se encuentran regulados y controlados por la ley. ${ }^{15}$

\section{III.2. ALCANCES DEL TÉRMINO SEGURIDAD PÚBLICA}

Aunque la expresión seguridad pública se invoca con frecuencia, no siempre las concepciones son precisas. $\mathrm{O}$ se suele generalizar demasiado el término englobando aspectos que atañen a la procuración, administración o ejecución de justicia penal, o se limita solamente al ámbito policial.

En el terreno funcional también es necesario delimitar el tratamiento de la seguridad pública. Se trata de un sistema que se ubica en uno más amplio: el sistema de justicia penal. Ahí se incorporan, principalmente, el ordenamiento jurídico-penal, la procuración y administración de justicia, el sistema penitenciario y el sistema especializado para adolescentes. Es decir, la seguridad pública es un subsistema que tiene relación con todo ello, pero no hay que confundir una parte con el todo. Como bien lo precisa Rojas: "un peligro en el debate de seguridad es su ampliación conceptual. No todo tema importante es un tema de seguridad. Tampoco todo tema de seguridad es per se un tema importante."16

Desde la perspectiva de su tratamiento, la seguridad pública es algo más que la ausencia de delitos. También es algo más que la organización de los servicios públicos.17 Es una relación entre la garantía de seguridad y el uso de la libertad. Es una de las tareas más complejas del Estado.

Apunta Pérez Canchola ${ }^{18}$ que la seguridad pública es un derecho humano imprescindible para ejercer otros derechos (en lato sensu los de tranquilidad y protección), e incluso tiene que ver con la manifestación plena del Estado de Derecho. Es importante porque constituye un elemento central de gobierno y gobernabilidad, dando al mismo tiempo sustento a la jus-

${ }^{14}$ Cfr. VITALE, Ermanno, “Democracia, derechos y uso de la fuerza pública”, en: Instituto Nacional de Ciencias Penales, El uso de la fuerza pública en un Estado democrático de Derecho, Memoria del Congreso Internacional celebrado en agosto de 2010, México, 2011, pp. 13-29.

${ }^{15}$ Ignacio Carrillo Prieto al respecto también ha dicho "Las ideas de control jurídico, de regulación desde el derecho de la actividad estatal y de limitación del poder del Estado por el sometimiento a la ley, resultan centrales para el concepto de Estado de Derecho, pero siempre estarán referidas al respeto a la persona humana y sus derechos fundamentales." Carrillo Prieto, Ignacio, "El Estado de derecho y la fuerza policial", en: Criminalia, Año LXVIII, No. 1, enero-abril, Academia Mexicana de Ciencias Penales, Editorial Porrúa, México, 2002, pp. 217 y 218.

${ }^{16}$ Citado por Barrón Cruz, Martín Gabriel, “Dilemas de la seguridad pública en México", en: Iter criminis, núm. 11, segunda época, méxico, instituto nacional de ciencias penales, julio-septiembre de 2004.

${ }^{17}$ Aunque Carrillo Prieto lo asimila, en cierta medida a los bienes de consumo público y a los servicios. Señala este autor: "la seguridad, en la sociedad moderna, es un bien de consumo como lo es, por ejemplo, la sanidad. La policía se enfrenta a la necesidad de racionalizar las estructuras haciendo su servicio más eficiente o, en caso contrario, la privatización progresiva de la seguridad convertirá a ésta en privilegio de quien pueda costearla." Carrillo Prieto, Ignacio, op. cit. p. 216. En terminología del derecho administrativo, la seguridad pública como servicio público ha de satisfacer una necesidad colectiva mediante organización y planeación de la administración pública, así, será consecuencia del grado político y de cultura alcanzado por una sociedad. Por lo tanto, la seguridad es corresponsabilidad Estado y ciudadanía, producto de una cultura sobre la legalidad (lato sensu), cuyo único destinatario es el hombre mismo.

${ }^{18}$ Vid. PéRez Canchola, José Luis, "La seguridad pública y la profesionalización del personal policial en la administración pública actual”, en: Seguridad Pública Nacional en México y en Francia. Memoria coloquio franco-mexicano sobre seguridad pública nacional, México, Secretaría de Gobernación, Embajada de Francia e Instituto Nacional de Administración, 1998, p. 123. 
ticia y al orden público. ${ }^{19}$ En ese sentido, Augusto Sánchez Sandoval señala que "la seguridad pública cumple una función conservadora del orden social con base en un orden jurídico que controla el poder y norma sus relaciones con los ciudadanos y de éstos entre sí." ${ }^{\circ}$

En otro sentido, la seguridad pública significa una garantía por el Estado y para el gobernado. Su contenido encierra un conjunto de acciones cuya orientación obedece al mínimo de condiciones necesarias que permitan coexistir libertades y derechos de los miembros en una sociedad específica, resultando así un ambiente de tranquilidad propicio para que se desarrollen con plenitud.

Sobre la conceptualización normativa, la Ley General del Sistema Nacional de Seguridad Pública -En lo sucesivo LGSNSP- ${ }^{21}$, reglamentaria del artículo 21 de la CPEUM, define a la seguridad pública en su artículo $2^{\circ}$ como:

Una función a cargo de la Federación, el Distrito Federal, los Estados y los Municipios, cuyo fin es la salvaguarda de la integridad y derechos de las personas, así como preservar las libertades, el orden y la paz públicos y comprende la prevención especial y general de los delitos, la investigación para hacerla efectiva, la sanción de las infracciones administrativas, así como la investigación y la persecución de los delitos y la reinserción social del individuo, en sus respectivas competencias.

Así, en el contexto mexicano, la función de la seguridad pública está dirigida a garantizar la "existencia y permanencia del orden público y privado como condición necesaria para la vida social." ${ }^{22}$ Es decir, lograr la convivencia armónica mediante una adecuada aplicación y cumplimiento de la ley, dando expedita solución a los problemas sociales, con miras de proporcionar tranquilidad a todo el cuerpo social.

\section{III.3. FUNCIÓN POLICIAL}

La función policial es una herramienta del Estado que tiene como finalidad mantener el orden social y luchar contra la delincuencia. ${ }^{23}$ Esto es, la función policial es uno de los medios para la consecución de la seguridad pública.

\section{III.3.1. EL USO DE LA FUERZA}

La policía tiene, entre sus funciones, las de prevenir y perseguir delitos, hacer cumplir las leyes y los reglamentos, salvaguardar el orden público y proteger los bienes jurídicos de los miembros de la comunidad. En ocasiones el cumplimiento de esos deberes supone la necesidad del empleo de la fuerza por parte de los miembros de los cuerpos policiacos.

\footnotetext{
${ }^{19}$ Cfr. Concepto de Seguridad pública en Estrella Ortega, Luis Alberto (compilador), Criterios Relevantes, segunda edición, México, Procuraduría de los Derechos Humanos del Estado de Guanajuato, 2008, pp. 17 y 18.

${ }^{20}$ Sanchez Sandoval, Augusto, Derechos Humanos, Seguridad Pública y Seguridad Nacional, México, Instituto Nacional de Ciencias Penales, 200o, p. 83.

${ }^{21}$ Esta norma quedó aprobada el 11 diciembre de 2008 y fue publicada en el Diario Oficial de la Federación el O2 de enero de 2009.

22 Sanchez Sandoval, op. cit., p. 83.

${ }^{23}$ Kala, Julio César, "Las políticas de seguridad, en busca de un modelo policial”, en: La Policía de Proximidad o Policía Comunitaria, México, (Sin más referencias bibliográficas).
} 
Es decir, para que el Estado pueda materializar la función de seguridad pública se auxilia de manera directa e inmediata de la policía, cuya función se encuentra regulada, a partir del artículo 21 de la CPEUM, ${ }^{24}$ que también establece los principios a los que sujetará su actuar. Dicho precepto especifica: "La actuación de las instituciones de seguridad pública se regirá por los principios de legalidad, objetividad, eficiencia, profesionalismo, honradez y respeto a los derechos humanos reconocidos en esta Constitución”.

La Suprema Corte de Justicia de la Nación en su pronunciamiento sobre dicha función ha referido que "el concepto de policía se relaciona con la actividad del Estado de vigilar el respeto a la ley para preservar el orden en la sociedad, lo que ha propiciado la creación de corporaciones especializadas para el cuidado del orden público y la paz de la comunidad en determinados sectores o actividades de la sociedad." 25

Así, el fin de la policía es brindar protección a la sociedad frente al crimen y el desorden público. Justifica su existencia en la apremiante necesidad de defender a la comunidad y garantizar el orden jurídico.

\section{III.3.2. EL PAPEL DE LA POLICÍA EN UN ESTADO DEMOCRÁTICO DE DERECHO}

En palabras de Ermanno Vitale: ${ }^{26}$ ¿Qué uso de la fuerza puede, o debe, hacer el Estado Democrático de Derecho?

En un Estado democrático la policía debe orientar su actuar bajo la inspiración de garantizar la seguridad pero dentro del marco de libertad. ${ }^{27}$ Cuando se sacrifica la libertad en aras de la seguridad se termina por perder ambas. No olvidemos que la función policial responde a la demanda del ciudadano; debido a ello, en la medida que cumpla sus expectativas tendrá la legitimidad y confianza social en su actuar.

En una sociedad libre y democrática la policía está al servicio de la ley y de las instituciones democráticas y su misión debe asegurar que el sistema creado no sea un instrumento de opresión. ${ }^{28}$

\section{ACTUACIÓN POLICIAL Y DERECHOS HUMANOS}

\section{IV.1. EL ACTUAR DEL POLICIA}

Los policías son los funcionarios públicos a quienes corresponde ejercer la prerrogativa estatal de uso de la fuerza y son, igualmente, los funcionarios con quien más contacto tiene la gente. Con base en ello, sostenemos como directriz de este trabajo la trascendencia de que los policías conozcan, por un lado, los principios y reglas para hacer uso de la fuerza y; por

\footnotetext{
${ }^{24} \mathrm{Al}$ establecer en su párrafo primero lo siguiente: "La investigación de los delitos corresponde al Ministerio Público y a las policías, las cuales actuarán bajo la conducción y mando de aquél en el ejercicio de esta función. (...)."

25 Tesis: 2a./J. 167/2006, página: 208 Policía de Vialidad y Tránsito del Estado de Jalisco. Sus oficiales se rigen Por el artículo 123, Apartado B, Fracción XIII de la Constitución Política de los Estados Unidos Mexicanos.

${ }^{26}$ Vid. Vitale, Ermanno, op. cit. p. 16.

${ }^{27}$ Vid. Guerrero Agripino, Luis Felipe. Seguridad pública y prevención del delito en el estado social de derecho. Especial comentario a la trascendencia de la educación, Guanajuato, Universidad de Guanajuato, 2007, p. 92.

${ }^{28}$ Vid. Núñez Pedraza, Manuel, “La Policía en la Prevención del Delito”, en: Carranza Elías (Coordinador), Delito y seguridad de los habitantes, Unión Europea, Siglo XXI editores, 1997, p. 163.
} 
otro lado, que sean formados en el conocimiento de los derechos humanos, como pautas y límites de su actuar.

\section{IV.2. APRECIACIÓN FENOMENOLÓGICA DEL ACTUAR POLICIAL}

El policía "actúa" con fundamento y en cumplimiento de las atribuciones constitucionales, legales y reglamentarias que lo regulan. Aun cuando lo idóneo es evitar complicaciones, la condición humana del policía, de sus interlocutores y la complejidad de las relaciones sociales, son susceptibles de provocar desenlaces indeseables.

El elemento policial debe visualizar toda una gama de variantes, para evitar incurrir en la probable comisión de ilícitos administrativos o penales y sujetarlo al respectivo procedimiento por considerar que ha incumplido con sus obligaciones y atribuciones encomendadas por ley.

\section{IV.2.1. LOS CUERPOS POLICIALES}

La institución de la policía está ligada al Sistema de Justicia Penal, es decir, a los ámbitos de prevención del delito, y de procuración, administración y ejecución de justicia; se organiza a través de cuerpos policiales, y éstos se ubican, respectivamente, en cada uno de los tres ámbitos de gobierno (municipal, estatal y federal).

Esta precisión es importante, pues aunque si bien la institución de policía es una sola, se encuentra diseccionada por tres ámbitos de gobierno y por variadas esferas de competencia, lo cual adquiere relevancia precisamente, para determinar, en los casos concretos, si su actuación policial se ajusta o no al marco normativo vigente, y por ende, cuándo es legítimo su actuar o cuándo es ilegítimo, de origen. Pero también es importante por cuestiones de apreciación cualitativa, como la cultura e identidad policial, sus estructuras organizacionales, su realidad institucional, su grado y calidad en la vinculación con la comunidad, etc.

\section{IV.2.2. EL ACTO DE AUTORIDAD}

El acto de autoridad es la materia, el motivo o la causa de acercamiento del policía al gobernado. Es el supuesto de hecho o de derecho que motiva la intervención policial. Necesariamente tiene que derivarse del marco normativo de actuación de ese cuerpo policial en particular. De tal suerte que habría primero que identificar a qué cuerpo policial pertenece, en qué ámbito de gobierno se ubica, cuál es su ámbito de competencia específica de todo el universo de actuación que tiene a su cargo la policía, y en consecuencia, el marco normativo general y específico de su actuación (internacional, constitucional, legal, reglamentario y técnico).

Aunado a lo anterior, también es importante resaltar que la materia (acto de autoridad específico) tiene relevancia para definir, en cierta medida, cómo el policía entrará en contacto con el gobernado. Es decir, el diseño de la estrategia de su actuación. De tal suerte que no es lo mismo prevenir la comisión de un probable hecho delictuoso, perseguir a un probable delincuente, cuidar una manifestación pacífica (legal o ilegal), detener a un conductor ebrio 
o arrestar por alguna falta administrativa a los bandos de policía y buen gobierno, entre otros múltiples supuestos.

\section{IV.4. TRASCENDENCIA DEL RESPETO A LOS DERECHOS HUMANOS EN LA ACTUACIÓN POLICIAL}

El respeto a los derechos humanos, no solo de la policía, sino de cualquier autoridad estatal no es una potestad es un imperativo. Ahora bien, aunado a la trascendencia per se que deriva de dicha obligación, existen otras bondades, todas ellas inciden en el fortalecimiento del Estado democrático. Al respecto, Joaquín Villalobos29 relaciona 5 razones que hacen altamente costeable que la policía respete los derechos humanos: 1) Mantienen la cohesión social. El uso excesivo de la fuerza contra los grupos de criminalidad trae como consecuencia una sociedad fragmentada. Una sociedad dividida es una sociedad débil, los derechos humanos sirven para mantener integrada a la población en torno a la legalidad y para aislar la violencia. 2) Garantizan el ciclo de información instituciones-ciudadanos. Cuando el Estado actúa abusando de la fuerza, crea una relación de miedo para con sus ciudadanos, multiplicando la desconfianza hacia las Instituciones. Los derechos humanos crean confianza, resultado una relación dinámica entre la sociedad y el Estado para prevenir y perseguir el delito. 3) Mantienen la ventaja moral del Estado. Si el Estado abusa de la fuerza, se pone al mismo nivel que los grupos antisociales. Lo cual va en contra de su calidad de educador de la ciudadanía, de los principios de legalidad y de ejemplo para la no violencia. Por el contrario, cuando el Estado es respetuoso de los derechos humanos se coloca en un estatus superior de legalidad y paz, dándole mayor legitimación al cuerpo policial en su intervención 4) Protegen la calidad humana y la salud mental de los servidores públicos. El Estado está obligado a poner límites en el empleo de la fuerza de sus agentes, de no hacerlo corre el riesgo de generar inseguridad provocada por las autoridades encargadas de velar por la seguridad. 5) Evitan la multiplicación de la violencia. El Estado debe fomentar el uso inteligente y racional de la fuerza, eliminar toda posibilidad de autoritarismo.

\section{GENERALIDADES SOBRE EL USO DE LA FUERZA POLICIAL}

\section{V.1. COMENTARIO INICIAL}

La policía, al estar destinada a remover y afrontar peligros que amenazan el libre desenvolvimiento individual y colectivo, queda obligada a que en su acción deba conformarse a la naturaleza, el grado y la índole del peligro de que se trate. Ahí radica su responsabilidad para no traspasar los límites legales contemplados en el sistema nacional de seguridad pública. Recordemos, pesa sobre él la presunción legal de estar en aptitud para identificar naturaleza, cantidad y calidad del peligro que por obligación afronta, y, por tanto, prevenir los medios idóneos para vencerle.

\footnotetext{
${ }^{29}$ Villalobos, Joaquín, "El Estado y el uso responsable de la fuerza”, en: Medina Mora Icaza, Eduardo, coordinador, Uso Legítimo de la Fuerza, México, Instituto Nacional de Ciencias Penales, 2008, pp. 175 - 181. 


\section{V.2. CONCEPTO}

El uso de la fuerza pública ${ }^{30}$ es uno de los instrumentos con los cuales cuenta el Estado, a través de sus cuerpos policiales, para desempeñar sus atribuciones y hacer cumplir sus determinaciones. De manera que "el policía debe usar solamente la fuerza que un policía razonablemente prudente utilizaría en las mismas circunstancias o en circunstancias parecidas." ${ }^{31}$ Bajo este contexto, la legitimación inherente a su función para el uso de la fuerza se reduce expresamente por principios ${ }^{32}$ recogidos en la LGSNSP, reglamentaria del artículo 21 de la CPEUM.

Oliveira y Proenca afirman que la policía es una respuesta al desafío de producir enforcement sin que esto le lleve a la tiranía o pase a servir a intereses particulares. Así el uso de la fuerza policial tiene como propósito producir alternativas pacíficas de obediencia bajo consentimiento social, en el imperio de la ley. Ello corresponde a que el uso de la fuerza tiene fines restrictos y transparentes, de tales maneras y con tales controles que los salvaguarda de convertirse en herramienta de opresión. ${ }^{33}$

Es criterio aceptado que el Estado debe hacer frente a quienes pongan en peligro a la sociedad política, pero debe hacerlo dentro de ciertas coordenadas. ${ }^{34}$ Por tanto, el uso de la fuerza legítima debe presentarse de manera excepcional y limitada. Es decir, su uso será el último recurso por medio del cual se pretende impedir un hecho de mayor gravedad que el que provoca la reacción estatal.

Carrillo Prieto habla del modelo de intervención policial garantista, y establece que su propósito está en "conferir el máximo de seguridad para la sociedad que no delinque y el mínimo de violencia para el infractor y el delincuente". ${ }^{35}$

\section{V.3. DIFICULTAD E IMPORTANCIA DE LA DEFINICIÓN}

Aun y cuando pareciera tarea sencilla decidir cuándo nos encontramos en presencia de un caso justificado u otro injustificado de uso de la fuerza pública, en realidad no es tarea sencilla. Hay casos de uso excesivo, tan evidentes, que hacen parecer como innecesario trabajar en una definición. Sin embargo, de cada uno de estos casos, por muy notorios que sean, se derivan parámetros o criterios de lo que "debieron haber hecho" los policías para sujetar su actuar a lo legítimo. Lo mismo ocurre también con aquellos casos que no son tan claros, y se encuentran en un ámbito de indefinición demasiado delgado entre lo legítimo y lo ilegítimo. ${ }^{36}$

\footnotetext{
30 Sobre este tema, también puede verse Peñaloza, Pedro José, Notas graves y agudas de la seguridad pública, México, Instituto Nacional de Ciencias Penales, 2003.

${ }^{31}$ INSTITUTO PARA LA SEGURIDAD Y LA DEMOCRACIA, A.C. (INSYDE), "Políticas y protocolos institucionales para el uso de la fuerza”, México, Centro de Certificación Profesional de Agencias Policiales, 2008, p.13, disponible en: www.insyde.org.mx

${ }^{32}$ Vid. Infra. Principios a los que debe sujetarse el uso de la fuerza policial.

${ }^{33}$ De Oliveira Muñiz, Jacqueline y Proenca Júnior, Domício, "Bases conceptuales de métricas y patrones de medida del desempeño policial", en: Red de policías y sociedad civil, p.336.

34 Ibarra Palafox, Francisco. "El Leviatán encadenado o la legitimidad de la violencia estatal”, en: Medina Mora Icaza, Eduardo, coordinador, Uso Legítimo de la fuerza, México, Instituto Nacional de Ciencias Penales, 2008, p. 23.

${ }^{35}$ Carrillo Prieto, Ignacio, op. cit., p. 229.

36 "Esta dificultad se deriva de algunos impedimentos. Uno ellos es la ausencia de descripciones objetivas del acontecimiento (comportamiento ciudadano y policial en el encuentro, entre otros aspectos), dado que tanto los efectivos que emplean la fuerza como los ciudadanos que son el blanco de la misma, tienden a elaborar relatos diferentes sobre lo acontecido.” BIRKBECK, Christopher y GABALDÓN, Luis Gerardo (editores), "Conclusión. La definición de los usos Justificados de la fuerza en el desempeño policial: propuestas para un proyecto de investigación comparada”, en: Policía y fuerza física en perspectiva Intercultural, Nueva Sociedad, Caracas, 2003, p. 128.
} 
Al respecto, Christopher Birkbeck y Luis Gerardo Gabaldón ${ }^{37}$ señalan que una dificultad en la evaluación de la actuación policial, es la complejidad potencial y la variedad evidente de las tentativas de definir el uso justificado de la fuerza. Así, una evaluación más estricta del comportamiento policial nos obliga a examinar los criterios con base en los cuales se juzga la fuerza como racional o irracional. Solo el estudio de esa problemática en una variedad de ámbitos o jurisdicciones nos permitirá iniciar una revisión adecuada de nuestras propias concepciones de la fuerza justificada. ${ }^{38}$

\section{V.4. USO EXCESIVO DE LA FUERZA POLICIAL}

Reiteramos, los linderos entre uso legítimo y el uso excesivo de la fuerza suelen ser muy estrechos, casi imperceptibles y fáciles de traspasar.

En la mayoría de las ocasiones, el uso excesivo de la fuerza tiene un origen de legalidad (es decir, existía el supuesto fáctico que facultaba la intervención estatal) pero en su ejercicio fue excedido su límite. Dicho en otras palabras, en un escenario específico se suscita un acontecimiento donde requieren intervenga el Estado a través de sus cuerpos policiales, haciendo uso legítimo de la fuerza policial. Bajo ese antecedente de legalidad, pueden presentarse distintos supuestos, donde lo legal se transforma en excesivo: a) Comienza haciendo uso legal de la fuerza, pero en la dinámica de los hechos, la fuerza va subiendo de intensidad y se excede. b) Comienza de inmediato con un uso ilegítimo de la fuerza policial, al dejar de observar los principios que rigen su aplicación.

\section{PRINCIPIOS A LOS QUE DEBE SUJETARSE EL USO DE LA FUERZA POLICIAL}

\section{VI.1. PRINCIPIOS FUNDAMENTALES}

Los principios fundamentales a los que debe sujetarse el uso de la fuerza policial son todas aquellas directrices que marcan el correcto actuar de los policías legitimando con ello el uso de la fuerza utilizada. ${ }^{39}$ En el contexto nacional, la LGSNSP expresamente decreta los principios que regu-

37 Ídem. También, estos mismos autores señalan: "En la sociedad contemporánea, los juicios sobre la justificación de la fuerza empleada por la policía se basan en "la situación". Por ejemplo, la justificación del uso del arma de fuego depende (entre otras cosas) del comportamiento del ciudadano. Así, disparar contra un ciudadano quien, simultáneamente, dispara a la policía podría considerarse justificable; disparar contra una persona desarmada que se está fugando luego de la comisión de un delito podría considerarse injustificado. Sin embargo, la "situación" puede referirse a muchas cosas, como por ejemplo, el estatus y comportamiento del ciudadano, el estado de ánimo, entrenamiento y objetivos del funcionario policial, y las características físicas del lugar donde ocurre el encuentro. Las concepciones de esa situación podrían variar en grado de detalle y contenido y se relacionarán, evidentemente, con los juicios sobre la justificación de la fuerza empleada."

${ }^{38}$ a) La policía de diversos países registra distintos niveles de fuerza en sus encuentros con los ciudadanos, y existe, a su vez, distinto nivel de sensibilidad frente a la utilización de la fuerza, tanto en lo que se refiere a situaciones como a intensidad. b) La tecnología y la predictibilidad para la resolución del encuentro parece ser una variable importante. Países con mayores recursos pueden invertir más en lo que se entiende como "capital social de la policía", tanto en términos de condiciones laborales como de dotación, equipos y tecnología de intervención, incluyendo situaciones críticas. c) Las normas de actuación parecen ser generales y bastante similares en todos los contextos, lo cual indica que ellas mismas no explican el uso diferencial de la fuerza y que existen variables extralegales, que se vinculan al encuentro con el ciudadano y a las justificaciones o legitimaciones del uso de la fuerza, que pueden contribuir a explicar el desempeño policial. Ello confiere relevancia al discurso de justificación sobre el uso de la fuerza. Gabaldón, Luis Gerardo y Birkbeck, Christopher (Organizadores), Informe Sumario sobre el Taller Internacional sobre Violencia Policial, Mérida, Caracas, 2001, p. 5-6.

39 Desde la academia, el Instituto Ciudadano de Estudios sobre la Inseguridad (ICESI), propone una serie de premisas para el empleo de la fuerza legítima por parte de los agentes policiacos, vid. INSTITUTO CIU- 
larán el uso de la fuerza que ejercen los cuerpos de seguridad pública en cumplimiento de sus funciones:

Artículo 41.- Además de lo señalado en el artículo anterior, los integrantes de las Instituciones Policiales, tendrán específicamente las obligaciones siguientes:

$\mathrm{I}-\mathrm{XI}(\ldots)$

Siempre que se use la fuerza pública se hará de manera racional, congruente, oportuna y con respeto a los derechos humanos. Para tal efecto, deberá apegarse a las disposiciones normativas y administrativas aplicables, realizándolas conforme a derecho." 40

El legislador estimó lo siguiente respecto de los puntos de contacto entre las policías e infractores:

(...) tienen diferentes aristas en las que el principio de legalidad debe hacerse valer, así como también el principio de la debida diligencia, que sustituye al viejo concepto del cumplimiento del deber hasta la última de sus consecuencias y por todos los medios posibles, hecho que ha propiciado el surgimiento de incentivos y márgenes de acción, sobre la base de reglas informales o formales, a la conducta ilegítima y el abuso de la fuerza. ${ }^{41}$

También, el legislador ha considerado que:

La actuación de la policía debe contar con un marco normativo que le brinde seguridad jurídica; al mismo tiempo que la ciudadanía debe conocer y saber cuáles son los límites del uso de la fuerza pública en los procedimientos policiales. Ambos aspectos (...) siguen presentando controversias sobre el grado de apego que tiene diversos procedimientos policiales con respeto a los derechos humanos de los sujetos que debido a las circunstancias delictivas, son sometidos por los policías. No hay policía democrática cuando ésta no regulariza la relación armónica con los derechos humanos, cuando sus miembros no son reconocidos como autoridad con plenos derechos y obligaciones, y cuando el uso de la fuerza no es sujeto de control que garantice, al mismo tiempo, su eficacia y uso legítimo. ${ }^{42}$

Se legisló a fin de inducir criterios técnicos, operativos, de procedimiento y de responsabilidad policial que permitan evidenciar claridad en su intervención; anteriormente el parámetro quedaba sujeto a preceptos insertos en manuales, códigos de ética y otros instrumentos secundarios. La legitimidad en el uso de la fuerza de la cual son investidos los servidores públicos queda convalidada con la aplicación de límites (criterios homogéneos).

DADANO DE ESTUDIOS SOBRE LA INSEGURIDAD (ICESI), Op. cit., pp. 4-6. Francisco Ibarra Palafox, establece también una serie de criterios, parámetros o principios que tendrían que regular el uso legítimo de la fuerza policial; lo interesante de su aportación, es el matiz que le da a ese uso de la fuerza pública, en el contexto actual que vive México: La lucha contra la delincuencia organizada, y particularmente, al narcotráfico. Vid. Ibarra Palafox, Francisco, op. cit., pp. 24-26.

${ }^{40}$ Lo subrayado es propio.

${ }^{41}$ Dictamen de la Comisión de Seguridad Pública, con proyecto de decreto que expide la Ley General del Sistema Nacional de Seguridad Pública, en la Gaceta Parlamentaria de la Cámara de Diputados, número 2648-IV, jueves 4 de diciembre de 2008. Lo subrayado es propio.

${ }^{42}$ Ídem. Lo subrayado es propio. 
Así, continúa diciendo el legislador:

La inclusión de la regulación de los procedimientos policiales (...) abre la posibilidad de que la Federación, el Distrito Federal, los estados y los municipios, establezcan, dentro del ámbito de sus respectivas competencias, las normas de actuación en los distintos procedimientos al tenor de principios generales que garanticen un desempeño uniforme de la función de la seguridad pública en las corporaciones policiales. ${ }^{43}$

El ánimo legislativo parece orientado a instituir principios fundamentales en la actuación de los agentes e instituciones de seguridad pública, tomando como punto de partida los de legalidad, objetividad, eficiencia, profesionalismo, honradez y respeto a los derechos humanos establecidos por el párrafo $9^{\circ}$ del artículo 21 de la CPEUM ${ }^{44}$; a ellos habría que agregar entonces los de legalidad, racionalidad, congruencia, y oportunidad, establecidos por la citada LGSNSP.

\section{A) PRINCIPIO DE LEGALIDAD}

$\mathrm{Al}$ asumir la esencia de este principio, los policías únicamente están facultados para realizar aquellas actividades que el marco normativo específicamente les encarga. Así, el agente policial puede utilizar la fuerza solo con motivo del cumplimiento que le impone la ley y basarse en protocolos y técnicas adecuados, con apego a derecho para la prevención y arresto derivados de infracciones administrativas y conductas delictivas.

\section{B) PRINCIPIO DE RACIONALIDAD}

Se refiere a que el uso de la fuerza esté justificado por las circunstancias específicas y acorde a la situación que se enfrenta. ${ }^{45}$ Para Yáñez Romero ${ }^{46}$ este principio impone, también, a cada agente y a cada jefe la preparación de un plan de acciones frente al riesgo y sus peligros. Es un elemento clave para la toma de decisiones ante factores desencadenantes de riesgo, es decir, el elemento policial puede utilizar estratégicamente la fuerza una vez que ha identificado todos los factores que concurren en aquel supuesto.

\section{C) PRINCIPIO DE CONGRUENCIA}

Se traduce en la adecuación de la técnica concreta a una situación determinada. El elemento debe optar de entre todos los medios legalmente reconocidos el que resulte más idóneo. Dicha consideración estriba en la menor lesividad y restauración del orden. ${ }^{47}$

\footnotetext{
43 Ídem. Lo subrayado es propio.

44 El párrafo $9^{\circ}$ del artículo 21 de la Constitución Política de los Estados Unidos Mexicanos establece: “...La actuación de las instituciones de seguridad pública se regirá por los principios de legalidad, objetividad, eficiencia, profesionalismo, honradez y respeto a los derechos humanos reconocidos en esta Constitución.”

${ }^{45}$ Dirección de Investigación del Instituto de Formación Profesional: Ley que regula el Uso de la Fuerza de los Cuerpos de Seguridad Pública del distrito Federal (Comentada), Colección de Estudios Legislativos, México, 2008, p. 65.

${ }^{46}$ Yañez Romero, José Arturo, “Comentario al artículo 8” en: Ley que regula el uso de la fuerza de los cuerpos de seguridad pública del Distrito Federal, Comentada, Colección de Estudios Legislativos, Dirección de Investigación del Instituto de Formación Profesional, México, 2008, p. 72.

47 Swatmadrid, "Medios no letales en el uso policial de la fuerza", p. 1, disponible en: www.swatmadrid.com 


\section{D) PRINCIPIO DE OPORTUNIDAD}

Su alcance queda definido como la adecuación al momento concreto de la intervención. De esta manera, ante un supuesto concreto de la operativa policial el agente deberá determinar si es necesario el empleo de la fuerza; y en el caso de que así sea, optar por el medio y la técnica adecuada a ejercer, y por ende la intensidad con que debe aplicarlas." 48

\section{E) PRINCIPIO DE ESTRICTA NECESIDAD}

Se refiere a usar la fuerza y armas de fuego solamente cuando sea estrictamente necesario, en la medida que lo requiera el desempeño de sus tareas y cuando otros medios resulten ineficaces o no garanticen de ninguna manera el logro del resultado previsto y utilizar en la medida de lo posible, medios no violentos antes de recurrir al empleo de la fuerza y de armas de fuego. ${ }^{49}$

F) PRINCIPIO DE PROPORCIONALIDAD

Se traduce en actuar con moderación, de manera proporcional a la gravedad del delito y al objetivo legítimo que se persiga, y acudir al empleo de las armas de fuego sólo cuando resulte inevitable. También conlleva reducir al mínimo los daños y lesiones y evitar el empleo de la fuerza o, si no es posible, limitarla al mínimo necesario para el sometimiento. ${ }^{50}$

\section{VI.2. DIRECTRICES COMPLEMENTARIAS}

Como directrices complementarias, podríamos ubicar aquellas pautas que sirven como base de extensión, aplicación e interpretación de los principios fundamentales, para regular el uso adecuado de la fuerza policial.

\section{A) USO DIFERENCIADO}

No se podrá tratar igual a un delincuente habitual que a un ciudadano infractor; siempre el actuar dentro del uso de la fuerza, como se lleva dicho, debe regirse respetando los derechos humanos de las persona. Tratándose de situaciones distintas, el agente diferenciará de entre los niveles de escala cuál es aplicable, v.gr distinto es un ciudadano infractor al delincuente que lesiona bienes jurídicos relevantes; por

\footnotetext{
48 Ídem.

49 Procuraduría de los Derechos Humanos del Estado de Guanajuato y Secretaría de seguridad Pública del Estado de Guanajuato, op. cit. p. 7.

50 También descrito como la "adecuación entre la técnica o medio empleado, el bien jurídico protegido y el resultado. Esto es, utilizar fuerza de modo justo a la situación que originó la intervención de los agentes, debiendo actuar con decisión y sin demora, pero al mismo tiempo sin emplear técnicas policiales excesivas, peligrosas o inhumanas.” Por disposición legal el agente se obliga a emplear la fuerza, sí y sólo si, observa la escala progresiva en proporción a la situación. Swatmadrid, op. cit., p.1.
} 
tanto optará por ejercer con moderación y actuar en proporción a la gravedad de la falta administrativa o delito, y al objetivo legítimo de la seguridad pública. ${ }^{51}$

\section{b) Mínima lesión o daÑo}

Las leyes y diversos tratados internacionales disponen que todo servidor encargado de hacer cumplir la ley deberá de estar provisto de una capacitación adecuada, para cuidar la integridad física de todo detenido y procurar respetar los derechos humanos de la ciudadanía e incluso de los delincuentes, siendo innecesario el uso excesivo de la fuerza una vez incapacitado el sospechoso, o bien cuando no represente un peligro para el elemento policial o la sociedad..$^{52}$

\section{C) AUXILIO MÉDICO}

Siempre se debe priorizar la salvaguarda de la vida de un ser humano, no puede ni debe restringirse el auxilio a un sospechoso, incluso al que trato de privar de la vida a otro. El principio de referencia exige que posterior a un enfrentamiento armado, por las lesiones ocasionadas al detenido, con prontitud e inmediatez se procure su atención médica y la certificación correspondiente para evitar se auto inflija lesiones. Es importante dejar evidencia de ello porque deja constancia de un uso de la fuerza en forma proporcional y con estricto apego a derecho, para evitar le imputen responsabilidad alguna53.

\section{D) RENDICIÓN DE INFORMES}

Los gobiernos y los organismos respectivos deben diseñar y operar procedimientos eficaces para la presentación de informes y que autoridades administrativas o judiciales independientes estén dotadas de competencia en circunstancias apropiadas. En caso de muerte y lesiones graves u otras consecuencias de importancia, se enviará rápidamente un informe detallado a las autoridades competentes para la revisión administrativa y la supervisión judicial. ${ }^{54}$

\section{RÉGIMEN JURÍDICO DEL USO DE LA FUERZA}

VII.1. ORDEN JURÍDICO NACIONAL

Para contextualizar el marco jurídico que regula el uso de la fuerza policial, de manera general, es necesario atender al conjunto de preceptos constitucionales, legales, reglamentarios y administrativos que son el marco regulatorio del sistema nacional de seguridad pública y que también establecen el régimen jurídico fundamental de la función y la actuación policial en los tres ámbitos de gobierno y en las distintas esferas de competencia, y que por obviedad

\footnotetext{
${ }^{51}$ Vid. Supra. Apreciación Fenomenológica del Actuar Policial.

${ }^{52}$ Principios básicos sobre el empleo de la fuerza y de armas de fuego por los funcionarios encargados de hacer cumplir la ley.

${ }^{53}$ Escuela Profesional de la Policía Federal de Caminos. Clase Táctica Policial, México, 1998.

${ }^{54}$ Principios básicos sobre el empleo de la fuerza y de armas de fuego por los funcionarios encargados de hacer cumplir la ley.
} 
de espacio no podremos abordar en esta oportunidad. De manera específica, habría que resaltar lo establecido por el artículo 21 de la CPEUM, párrafo noveno, y el artículo 41 de la LGSNSP ya vistos.

Como se ha señalado, el Distrito Federal es la única entidad federativa que cuenta con una ley y un reglamento de la materia. En el ámbito federal, hasta el momento se ha preferido abordar este tema a través de protocolos de actuación de reciente cuño:

a) ACUERDO A/079/12 de la Procuradora General de la República, por el que se establecen las directrices que deberán observar los servidores públicos de la institución para la detención y puesta a disposición de personas, publicado en el Diario Oficial de la Federación (cuarta sección) del 23 de abril del 2012.

b) ACUERDO A/080/12 de la Procuradora General de la República, por el que se establecen las directrices que deberán observar los agentes de la policía federal ministerial para el uso legítimo de la fuerza, publicado en el Diario Oficial de la Federación (cuarta sección) del 23 de abril del 2012.

c) ACUERDO 04/2012 del Secretario de Seguridad Pública, por el que se emiten los lineamientos generales para la regulación del uso de la fuerza pública por las instituciones policiales de los órganos desconcentrados en la Secretaría de Seguridad Pública, publicado en el Diario Oficial de la Federación (cuarta sección) del 23 de abril del 2012.

d) ACUERDO 05/2012 del Secretario de Seguridad Pública, por el que se emiten los lineamientos generales para poner a disposición de las autoridades competentes a personas u objetos, publicado en el Diario Oficial de la Federación (cuarta sección) del 23 de abril del 2012.

e) ACUERDO Secretarial 27 por el que se reforma y adiciona la Directiva 003/09 del 30 de septiembre de 2009, mediante la cual se regula el uso legítimo de la fuerza por parte del personal naval, en cumplimiento del ejercicio de sus funciones, en coadyuvancia al mantenimiento del Estado de Derecho, publicado en el Diario Oficial de la Federación (cuarta sección) del 23 de abril del 2012.

f) DIRECTIVA que regula el uso legítimo de la fuerza por parte del personal del Ejército y Fuerza Aérea Mexicanos, en cumplimiento del ejercicio de sus funciones en apoyo a las autoridades civiles y en aplicación de la Ley Federal de Armas de Fuego y Explosivos, publicado en el Diario Oficial de la Federación (cuarta sección) del 23 de abril del 2012.

g) CONVENIO de Colaboración en el marco del respeto a los derechos humanos que celebran la Secretaría de Gobernación, la Secretaría de la Defensa Nacional, la Secretaría de Marina, la Procuraduría General de la República y la Secretaría de Seguridad Pública Federal, publicado en el Diario Oficial de la Federación (cuarta sección) del 23 de abril del 2012. 


\section{VII.2. ORDEN JURÍDICO INTERNACIONAL}

Múltiples instrumentos internacionales en materia de derechos humanos se vinculan estrechamente con nuestro tema; en términos generales tenemos: ${ }^{55}$

a. 1948. Declaración Universal de los Derechos Humanos. ${ }^{56}$

b. 1955. Reglas Mínimas para el Tratamiento de los Reclusos. ${ }^{57}$

c. Declaración Americana de los Derechos y Deberes del Hombre. ${ }^{58}$

d. 1966. Pacto Internacional de Derechos Civiles y Políticos. ${ }^{59}$

e. 1966. Protocolo Facultativo del Pacto Internacional de Derechos Civiles y Políticos. ${ }^{60}$

f. 1969. Convención Americana sobre Derechos Humanos. ${ }^{61}$

g. 1975. Declaración sobre la protección de todas las personas contra la tortura y otros tratos o penas crueles, inhumanas o degradantes. ${ }^{62}$

h. 1979. Código de conducta para funcionarios encargados de hacer cumplir la ley. ${ }^{63}$

i. 1984. Convención contra la Tortura y otros Tratos o Penas Crueles, Inhumanas o Degradantes. ${ }^{64}$

j. 1985. Declaración sobre los principios fundamentales de justicia para las víctimas de delitos y del abuso del poder. ${ }^{65}$

55 A los que se suman otros vinculados a los derechos humanos en general, a las mujeres, a los niños, a los adolescentes, reclusos, medidas substitutivas, tortura, pena capital, prevención del delito, víctimas, gobernanza, justicia penal, derecho humanitario, etc.

${ }^{56}$ Proclamado por la Asamblea General de las ONU mediante la Resolución 217 A (III) de 10 de diciembre de 1948.

57 Proclamadas por el Primer Congreso de las Naciones Unidas sobre Prevención del Delito y Tratamiento del Delincuente, celebrado en Ginebra, Suiza, el 30 de agosto de 1955. Aprobadas también por el Consejo Económico y Social de la ONU en 1957 (Resolución 663 C (XXIV) del 31 de julio de 1957, enmendada mediante Resolución 2076 (LXII) del 13 de mayo de 1977.

${ }^{58}$ Aprobada en la IX Conferencia Internacional Americana, en Bogotá, Colombia, 1948.

59 Proclamado por la Asamblea General de las ONU mediante la Resolución 2200A (XXI), de 16 de diciembre de 1966. Entrada en vigor: 23 de marzo de 1976, de conformidad con el artículo 49. Ratificado por México en 1981.

${ }^{60}$ Adopción: Nueva York, EUA, 16 de diciembre de 1966. Adhesión de México: 15 de marzo de 2002. Decreto Promulgatorio DOF 3 de mayo de 2002.

${ }^{61}$ Suscrita en San José de Costa Rica el 22 de noviembre de 1969, en la Conferencia Especializada sobre Derechos Humanos.

${ }^{62}$ Proclamado por la Asamblea General de la ONU en su resolución 3452 (XXX), de 9 de diciembre de 1975.

63 Proclamado por la Asamblea General de la ONU en su resolución 34/169, de 17 de diciembre de 1979.

${ }^{64}$ Adoptada y abierta a la firma, ratificación y adhesión por la Asamblea General en su resolución 39/46, de 10 de diciembre de 1984 entrando en vigor el 26 de junio de 1987.

${ }^{65}$ Proclamado por la Asamblea General de la ONU en su resolución 40/34, de 29 de noviembre de 1985. 


\section{k. 1985. Convención Interamericana para Prevenir y Sancionar la Tortura. ${ }^{66}$}

1. 1988. Conjunto de principios para la protección de todas las personas sometidas a cualquier forma de detención o prisión ${ }^{67}$

m. 1990. Principios básicos sobre el empleo de la fuerza y de armas de fuego por los funcionarios encargados de hacer cumplir la ley. ${ }^{68}$

n. 1990. Principios Básicos para el Trato a los Reclusos. ${ }^{69}$

o. 1992. Declaración sobre la Protección de todas las Personas contra las Desapariciones Forzadas. $^{70}$

p. 1994. Convención Interamericana sobre Desaparición Forzada de Personas. ${ }^{71}$

q. 1999. Protocolo de Estambul. Manual para la Investigación y documentación eficaces de la tortura y otros tratos o penas crueles, inhumanos o degradantes. ${ }^{72}$

r. 2002. Protocolo Facultativo de la Convención contra la Tortura y Otros Tratos o Penas Crueles, Inhumanos o Degradantes. ${ }^{73}$

s. 2008. Principios y Buenas Prácticas sobre la Protección de las Personas Privadas de Libertad en las Américas. ${ }^{74}$

Derivadas del trabajo del Alto Comisionado para los Derechos Humanos, al igual que del análisis de otros instrumentos internacionales como la Convención contra la tortura y otros tratos o penas crueles, inhumanos o degradantes, los Principios básicos sobre el empleo de la fuerza y armas de fuego, y las Reglas de justicia penal de las naciones unidas para la policía de mantenimiento de paz, de ahí se crean:

a) Normas Internacionales sobre el Uso de la Fuerza para todos los Funcionarios encargados de hacer cumplir la Ley.

b) Normas Internacionales sobre el arresto para todos los funcionarios encargados de hacer cumplir la Ley.

${ }^{66}$ Adoptada en la Asamblea General de la Organización de Estados Americanos, en su Décimoquinto Periodo Ordinario de Sesiones, en Cartagena de Indias, Colombia, el 9 de diciembre de 1985. Entrada en vigor 28 de febrero de 1987, conforme al artículo 22 de la Convención.

${ }^{67}$ Proclamado por la Asamblea General de la ONU en su resolución 43/173; fecha de adopción 9 de diciembre de 1988.

${ }^{68}$ Proclamado por el Octavo Congreso de las Naciones Unidas sobre Prevención del Delito y Tratamiento del Delincuente, celebrado en La Habana (Cuba) del 27 de agosto al 7 de septiembre de 1990.

${ }^{69}$ Aprobados por la Asamblea General de la ONU en su Resolución 45/III, del 14 de diciembre de 1990.

$7^{70}$ Aprobada por la Asamblea General en su resolución 47/133 de 18 de diciembre 1992.

${ }^{71}$ Adoptada en Belém do Pará, Brasil, el 9 de junio de 1994, en el vigésimo cuarto período ordinario de sesiones de la Asamblea General.

${ }_{72}$ Presentado a la Alta Comisionada de las Naciones Unidas para los Derechos Humanos el 9 de agosto de 1999.

${ }^{73}$ Adoptado por la Asamblea General de la ONU el 18 de diciembre de 2002. Publicado en el Diario Oficial de la Federación el 29 de marzo de 2005

${ }^{74}$ Resolución o1/08 de 13 de marzo de 2008 de la Comisión Interamericana de Derechos Humanos. 
c) Normas Internacionales sobre el Uso de la Fuerza para todos los Funcionarios con Responsabilidad de Mando y Supervisión.

d) Normas Internacionales sobre el Arresto para Funcionarios con Responsabilidad de Mando y Supervisión.

\section{ALGUNAS OPCIONES DE ABORDAJE A LA PROBLEMÁTICA PLANTEADA}

\section{VIII.1. COMENTARIO INICIAL}

¿Cómo podrán combatirse las deficiencias y abusos en el uso de la fuerza de los cuerpos policiales?

Ha quedado patente que el uso de la fuerza es una de las facultades o prerrogativas más problemáticas de la policía. Si los cuerpos policiales son los servidores públicos que más contacto tienen con la población, una corrección a aquella disfunción en el sistema es indispensable, y tendría que hacerse desde varias vertientes. Un problema estructural, merece soluciones estructurales que aporten, desde distintos ámbitos, a la solución integral del problema.

Así, atacar de raíz e institucionalmente el problema del uso inadecuado de la fuerza por parte de los cuerpos de policías requiere un abordaje desde diferentes ámbitos, A continuación, exploramos algunas alternativas.

\section{VIII.2. MARCO REGULATORIO ESPECÍFICO}

La construcción de un marco regulatorio específico no se agota en la existencia de una ley; es preciso pasar por los reglamentos, los manuales y los protocolos de actuación de los cuerpos policiales.

La necesidad de la existencia de este marco regulatorio se reconoce en los instrumentos internacionales. Los Principios básicos sobre el empleo de la fuerza y de armas de fuego por los funcionarios encargados de hacer cumplir la ley, ${ }^{75}$ establecen en su disposición general no. 1:

\footnotetext{
75 Proclamado por el Octavo Congreso de las Naciones Unidas sobre Prevención del Delito y Tratamiento del Delincuente, celebrado en La Habana (Cuba) del 27 de agosto al 7 de septiembre de 199o. Incluso, en su disposición general No. 11, hacen una serie de recomendaciones que deben contener dichas normas: Las normas y reglamentaciones sobre el empleo de armas de fuego por los funcionarios encargados de hacer cumplir la ley deben contener directrices que: a) Especifiquen las circunstancias en que los funcionarios encargados de hacer cumplir la ley estarían autorizados a portar armas de fuego y prescriban los tipos de armas de fuego o municiones autorizados; b) Aseguren que las armas de fuego se utilicen solamente en circunstancias apropiadas y de manera tal que disminuya el riesgo de daños innecesarios; c) Prohíban el empleo de armas de fuego y municiones que puedan provocar lesiones no deseadas o signifiquen un riesgo injustificado; $d$ ) Reglamenten el control, almacenamiento y distribución de armas de fuego, así como los procedimientos para asegurar que los funcionarios encargados de hacer cumplir la ley respondan de las armas de fuego o municiones que se les hayan entregado; e) Señalen los avisos de advertencia que deberán darse, siempre que proceda, cuando se vaya a hacer uso de un arma de fuego; f) Establezcan un sistema de presentación de informes siempre que los funcionarios encargados de hacer cumplir la ley recurran al empleo de armas de fuego en el desempeño de sus funciones.
} 
Los gobiernos y los organismos encargados de hacer cumplir la ley adoptarán y aplicarán normas y reglamentaciones sobre el empleo de la fuerza y armas de fuego contra personas por parte de funcionarios encargados de hacer cumplir la ley....

Como se ha hecho patente en diversos foros académicos ${ }^{76}$ desde la óptica del policía no existe claridad sobre qué implica el uso adecuado de la fuerza y no se cuenta con un manual procedimental que defina qué respuesta o qué acciones debe ofrecer ni en qué grado debe usarse la fuerza, dependiendo de cada situación. Esto apunta, en primer lugar, y a escala institucional, a acciones legislativas y reglamentarias para enmarcar jurídicamente el uso de la fuerza por aquellas personas encargadas de hacer cumplir la ley. La regulación normativa debería incluir, igualmente, mecanismos de "rendición de cuentas" que obliguen a los cuerpos policiacos a reportar y justificar las ocasiones en que deba hacerse uso de la fuerza o violencia, a fin de cuantificarla. ${ }^{77}$

Sobre este tema, hay distintas opiniones. Por un lado, hay quienes creen innecesario la creación de una ley y optan por los reglamentos. Por otro lado, quienes ven positivo regularlo también desde una ley, pasando por reglamentos y manuales.

Dentro de las posturas que no estiman conveniente la creación de una ley, destacan, por ejemplo, los argumentos del Instituto Ciudadano de Estudios sobre Inseguridad (ICESI), que establece las siguientes ideas: ${ }^{78}$

Los proyectos de ley que se han elaborado en México para regular este importante tema acusan deficiencias: son farragosos, extremadamente detallados y prevén tan desmesuradas exigencias para la utilización de la fuerza policiaca - un evento extraordinario de naturaleza criminal, de riesgo, violenta, intolerante, irracional, desmedida, radical, provocadora y lesiva- que prácticamente vedan este recurso.

Por otra parte, el asunto que nos ocupa no requiere una ley, pues la causa de justificación denominada cumplimiento de un deber está contemplada en la legislación penal de toda la República Mexicana, en el ámbito federal y en el fuero común. Las leyes, por su propia índole, no pueden prever todos los supuestos posibles, por lo que su nivel de generalidad y abstracción requiere ser amplio y omnicomprensivo, mientras que los reglamentos, en cambio, han de detallar y especificar los supuestos previstos en la ley a fin de que la aplicación del orden jurídico pueda hacerse de manera clara y unívoca. Por ende, el uso de la fuerza policial debe regularse en los reglamentos correspondientes.

En contrapartida, entre quienes sí apoyan la creación de una ley, destacan los argumentos sostenidos por el Instituto para la Seguridad y la Democracia (INSYDE) ${ }^{79}$, al señalar:

\footnotetext{
${ }^{76}$ Véase el cuaderno de trabajo "Policía y uso de la fuerza, una agenda clave de nuestra democracia", que presenta las reflexiones de la mesa debate del mismo nombre, organizada el 30 de noviembre de 2006 por el Instituto para la Seguridad y la Democracia, A.C.

77 Ídem. Pero además, de cualificarlas, de donde se derivaría información interesantísima para la toma de decisiones.

${ }^{78}$ Instituto Ciudadano de Estudios sobre la Inseguridad (ICESI). Propuesta para la aplicación legítima de la fuerza por parte de la policía, op. cit. p. 3 .

${ }^{79}$ Instituto para la Seguridad y la Democracia, A.C. (INSYDE). "Policía y uso de la fuerza, una agenda clave de nuestra democracia", op. cit. p. 9.
} 
... la tarea es aportar certidumbre, de modo que el policía entienda que está facultado para usar la fuerza, pero sólo en casos indispensables... La función de la policía es participar en el esfuerzo colectivo de garantizar la seguridad pública... Está encargada solamente de controlar, conducir y presentar ante las autoridades, y puede requerir usar la fuerza para cumplir estas funciones; pero, en todo caso, la policía no está facultada para actuar punitivamente, por lo que usar la fuerza para castigar queda fuera de los límites legítimos de su acción. Debe actuar siempre dentro de un marco de referencia legal.

Ahora bien, independientemente de las valiosas posturas académicas que existan a favor o en contra de la creación de cuerpos normativos de esta naturaleza, es importante recordar que el Presidente de los Estados Unidos Mexicanos y los representantes de los principales partidos políticos de México han suscrito un documento llamado Pacto por México ${ }^{80}$. Se trata de un documento que contiene cinco principales acuerdos: 1) Acuerdos para una sociedad de derechos y libertades; 2) Acuerdos para el crecimiento económico, el empleo y la competitividad; 3) Acuerdos para la seguridad y la justicia; 4) Acuerdos para la transparencia, rendición de cuentas y combate a la corrupción; y 5) Acuerdos para la gobernabilidad democrática. En cada uno de esos acuerdos, a su vez, se contienen diferentes ejes temáticos, en total son 34. Asimismo, en cada acuerdo se precisan concretamente diversos compromisos; por todos son $95 .{ }^{81}$ En su Compromiso No. 28 se señala: que como sucede en otros países, se creará una ley que establezca parámetros claros para el uso de la fuerza pública. Como se observa, la creación de una ley que regule el uso de la fuerza policial se visualiza actualmente en México como una prioridad de las principales fuerzas políticas del País.

VIII.3. IMPLEMENTACIÓN Y OPERACIÓN DEL SERVICIO PROFESIONAL DE LA CARRERA POLICIAL

Los principios básicos sobre el empleo de la fuerza y de armas de fuego por los funcionarios encargados de hacer cumplir la ley, establecen en su disposición general No. 18, relativa a calificaciones, capacitación y asesoramiento:

Los gobiernos y los organismos encargados de hacer cumplir la ley procurarán que todos los funcionarios encargados de hacer cumplir la ley sean seleccionados mediante procedimientos adecuados, posean aptitudes éticas, psicológicas y físicas apropiadas para el ejercicio eficaz de sus funciones y reciban capacitación profesional continua y completa. Tales aptitudes para el ejercicio de esas funciones serán objeto de examen periódico.

La CPEUM establece en su artículo 21, párrafo décimo, que las instituciones policiales de los tres órdenes de gobierno deberán coordinarse entre sí para cumplir los objetivos de la Seguridad Publica y conformarán el Sistema Nacional de Seguridad Publica, estableciendo para ello 5 bases mínimas, siendo la primera:

a) La regulación de la selección, ingreso, formación, permanencia, evaluación, reconocimiento y certificación de los integrantes de las instituciones de seguridad pública. La

\footnotetext{
${ }^{80}$ Suscrito el 2 de diciembre de 2012.

${ }^{81}$ Sobre el tema del Pacto por México, su descripción, sus alcances, y su vinculación con otro tema paralelo igual de importante al que estamos abordando, puede verse Guerrero Agripino, Luis Felipe, "La prevención desde fuera del sistema penal. Tendencias actuales del estado mexicano", en: Revista General de derecho Penal No. 19, Salamanca, España, 2013.
} 
operación y desarrollo de estas acciones será competencia de la Federación, el Distrito Federal, los Estados y los municipios en el ámbito de sus respectivas atribuciones.

Por otro lado, la LGSNSP, menciona en su artículo 72:

El Desarrollo Policial es un conjunto integral de reglas y procesos debidamente estructurados y enlazados entre sí que comprenden la Carrera Policial, los esquemas de profesionalización, la certificación y el régimen disciplinario de los integrantes de las instituciones policiales y tiene por objeto garantizar el desarrollo institucional, la estabilidad, la seguridad y la igualdad de oportunidades de los mismos; elevar la profesionalización, fomentar la vocación de servicio y el sentido de pertenencia, así como garantizar el cumplimiento de los principios constitucionales referidos en el artículo 6 de la Ley.

Así mismo, dicha LGSNSP en su artículo 78, prevé que:

La Carrera Policial es el sistema de carácter obligatorio y permanente, conforme al cual se establecen los lineamientos que definen los procedimientos de reclutamiento, selección, ingreso, formación, certificación, permanencia, evaluación, promoción y reconocimiento; así como la separación o baja del servicio de los integrantes de las Instituciones Policiales.

El título quinto de dicho cuerpo normativo establece los preceptos aplicables al Desarrollo Policial. Además, son dos los instrumentos técnicos normativos fundamentales que guían todo lo relativo al servicio profesional de carrera policial: el Sistema de Desarrollo Policial ${ }^{82}$ y el Programa Rector de Profesionalización. ${ }^{83}$

La LGSNSP, en su artículo 5, fracción XII concibe al Programa Rector de Profesionalización como el conjunto de contenidos encaminados a la profesionalización de los servidores públicos de las Instituciones Policiales e Instituciones de Procuración de Justicia, respectivamente.

Como se observa, en el ámbito mexicano existen las disposiciones normativas que prevén y regulan el servicio profesional de carrera policial. Sin embargo, no se cuenta con datos oficiales sobre su grado de implementación y operación en las distintas corporaciones de policía del País.

\section{VIII.3.1 RECLUTAMIENTO Y SELECCIÓN}

Un aspecto que incide en el fenómeno del uso excesivo de la fuerza policial se ubica desde el reclutamiento y selección de los elementos policiales. Se abren las siguientes interrogantes: ¿Quiénes aspiran a ser policías? Los que aspiran a serlo ¿por qué aspiran y para qué aspiran?

\footnotetext{
${ }^{82}$ Sistema Integral de Desarrollo Policial, México D.F., Secretaría de Seguridad Pública Federal, 2010, p.114.

${ }^{83}$ Secretariado Ejecutivo del Sistema Nacional de Seguridad Pública, Programa Rector de Profesionalización, México D.F., Secretaría de Gobierno Federal, 2010, p. 60.
} 


\section{VIII.3.2. PROFESIONALIZACIÓN ${ }^{84}$}

Distintos instrumentos internacionales refieren de manera reiterada la necesidad de capacitar a los elementos policiales en temas vinculados al uso de la fuerza policial.85 No obstante, contar con disposiciones jurídico-normativas no sería suficiente para subsanar el problema. Se requiere infundir valores, principios, conocimientos, habilidades y destrezas en los funcionarios encargados de hacer cumplir la ley. Las leyes, reglamentos y manuales de procedimientos deben estar necesariamente ligados con programas de profesionalización de los cuerpos policiales. ${ }^{86}$

En la praxis, la mayoría de los agentes para hacer cumplir la ley, cuando están ente un ciudadano reacio a obedecer a la autoridad, se apoyan de amenaza psicológica y la fuerza bruta. Diremos que esta deficiencia se subsana con la capacitación continua y la profesionalización de los cuerpos de seguridad.

La mala capacitación provoca un descontento generalizado por parte de la ciudadanía y desconfianza en el desempeño de los servidores públicos encargados de hacer cumplir la Ley. En síntesis, todo integrante del sistema nacional de seguridad pública debe contar con la debida capacitación que le permita estar muy bien capacitado para interpretar y actuar legítimamente en las circunstancias probables. ${ }^{87}$

\section{IX. ÚLTIMA CONSIDERACIÓN: LA IMPORTANCIA DEL CAPITAL SOCIAL DEL POLICÍA}

Comúnmente la parte visible de la actuación policial se palpa al momento de concretar su actuación y con mayor énfasis cuando es negativo. En las líneas previas hemos hecho referencia a aspectos eminentemente técnicos enfocados a cómo debe emplear la fuerza el agente policial. Pero detrás de todo ello está inmersa una realidad que quizás sea el corolario del tema que nos ocupa: las condiciones bajo las cuales el policía desarrolla su función; en otras palabras, el capital social del policía.

\footnotetext{
${ }^{84}$ Sobre este tema, puede verse con mayor detalle el "Capítulo IV. A modo de conclusión: Una respuesta a los problemas de uso de la fuerza desde la profesionalización de los cuerpos policiales", incluido en De Santiago Alvarez, Adriana, Función Policial y Uso legítimo de la Fuerza Pública. Una propuesta desde la perspectiva de profesionalización de los cuerpos policiales, tesis para la obtención del grado de Maestría en Ciencias Jurídico Penales por la Universidad de Guanajuato, México, sustentada el día 6 de diciembre de 2011.

${ }^{85}$ Vid. por ejemplo: a) Normas Internacionales sobre el Uso de la Fuerza para todos los Funcionarios encargados de hacer cumplir la Ley. b) normas Internacionales sobre el arresto para todos los funcionarios encargados de hacer cumplir la Ley c) Normas Internacionales sobre el Uso de la Fuerza para todos los Funcionarios con Responsabilidad de Mando y Supervisión y d) Normas Internacionales sobre el Arresto para Funcionarios con Responsabilidad de Mando y Supervisión.

${ }^{86}$ Métodos utilizados en materia del uso y empleo de la fuerza, asi como la capacitación de los cuertpos de seguridad, deben ser constantemetne revisados y evaluados por las autoridades correpondientes. Expediente de queja 160/o8-o; (...) La capacitación y cambios estructurales deben descansar en los siguientes ejes, a saber: (...) 5.- La seguridad pública es la piedra angular de la cual se vale el Estado para que el irrestricto apego de las atribuciones asignadas a los órganos responsables de velar por su complimiento, sea posible la coexistencia y la convivencia armónica, ordenada y respetuosa de sus miembros, para de esta manera garantizar- en la medida de lo razonablemente factible- que los seres humanos se encuentren en posibilidades reales de desarrollar sus potencialidades. (...) 8.- (...) es primordial que la actuación de los cuerpos policiacos se apegue a los principios de legalidad, eficiencia, profesionalismo y honradez establecidos en la carta magna. En conclusión toda policía debe asumirse como el principal protector de los derechos humanos (...).en Estrella Ortega, op. cit., pp. 27 y 28.

${ }^{87}$ Yañez Romero, op. cit., p. 73. 
El capital social de la policía son todos aquellos derechos, prestaciones y prerrogativas con los que cuenta un policía por desempeñar sus funciones y con motivo de ellas. Se las otorga el Estado y la sociedad por el hecho de ser policía, de desempeñar una de las funciones más importantes y peligrosas de la sociedad; es todo aquello que hace que "valga la pena ser policía”. Aquí encontramos sueldos, prestaciones, seguro de salud, seguro de vida, etc. Aunque algunos también incluyen en este concepto, todo el equipamiento indispensable para ejercer su función.

Mucho se ha dicho sobre la correcta conducción de las corporaciones, incentivar a sus miembros por una mejor capacitación, garantizarles un régimen de seguridad social de subsistencia básica y libre acceso a derechos para su desenvolvimiento social; son políticas tendientes a que el propio agente revalore la noción acerca de los derechos de los ciudadanos en general. En la medida que existan tales condiciones se incrementa la posibilidad de contar con servidores públicos revalorizados en la noción propia de su función en la sociedad. ${ }^{88}$

En la medida que el capital social del policía sea el idóneo, no solo se beneficia él, sino la sociedad en su conjunto. Si se aprecia desde el punto de vista humanitario es lo propicio por el nivel de exigencia que conlleva dicha función y si se quiere ver en términos pragmáticos, no es un gasto sino una inversión.

X. BIBLIOGRAFÍA

BARRÓN CRUZ, Martín Gabriel, “Dilemas de la seguridad pública en México”, en: Iter Criminis, núm 11, segunda época, México, Instituto Nacional de Ciencias Penales, julio-septiembre de 2004.

BENITO GARCÍA, José Ma., Manual básico de procedimientos de defensa personal policial, parte I, España, Cuerpo Nacional de Policía, División de formación y perfeccionamiento, Centro de actualización y especialización, 2009.

BIRKBECK, Christopher y GABALDÓN, Luis Gerardo (editores), “Conclusión. La definición de los usos Justificados de la fuerza en el desempeño policial: propuestas para un proyecto de investigación comparada”, en: Policía y fuerza física en perspectiva Intercultural, Nueva Sociedad, Caracas, 2003.

CARRILLO PRIETO, Ignacio, "El Estado de derecho y la fuerza policial”, en: Criminalia, Año LXVIII, No. 1, enero-abril, Academia Mexicana de Ciencias Penales, Editorial Porrúa, México, 2002.

DE OLIVEIRA MUÑIZ, Jacqueline y PRONCA JÚNIOR, Domício, "Bases Conceptúales de Métricas y Patrones de Medida del Desempeño Policial” en: Red de Policías y Sociedad Civil.

DE SANTIAGO ÁLVAREZ, Adriana, Algunos apuntes a la construcción de la cultura de la paz como eje transversal de la vida social y de las políticas públicas del Estado de Guanajuato, ensayo presentado para acreditar el Diplomado de Medios Alternativos

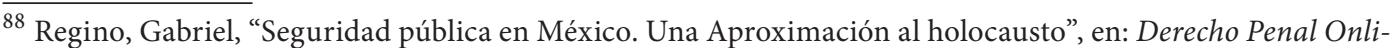
ne. Revista electrónica de doctrina y jurisprudencia en línea, consultado en junio 2009, disponible en: hppt:// www.derechopenalonline.com
} 
de Solución de Conflictos, Poder Judicial del Estado de Guanajuato, México, mayoagosto de 2011.

Función Policial y Uso legítimo de la Fuerza Pública. Una propuesta desde la perspectiva de profesionalización de los cuerpos policiales, tesis para la obtención del grado de Maestría en Ciencias Jurídico Penales por la Universidad de Guanajuato, México, sustentada el día 6 de diciembre de 2011.

DIRECCIÓN DE INVESTIGACIÓN DEL INSTITUTO DE FORMACIÓN PROFESIONAL, Ley que regula el Uso de la Fuerza de los Cuerpos de Seguridad Pública del distrito Federal (Comentada), Colección de Estudios Legislativos, México, 2008.

ESCUELA PROFESIONAL DE LA POLICÍA FEDERAL DE CAMINOS, Manual de Narcóticos, México, 1998.

a) Manual de Psicología, México, 1998.

b) Clase Táctica Policial, México, 1998.

ESTRELLA ORTEGA, Luis Alberto (compilador), Criterios Relevantes, segunda edición, México, Procuraduría de los Derechos Humanos del Estado de Guanajuato, 2008.

GABALDÓN, Luis Gerardo y BIRKBECK, Christopher (Organizadores), Informe Sumario sobre el Taller Internacional sobre Violencia Policial, Mérida, Caracas, 2001.

GARCIA CORDERO, Fernando, "Empleo de la fuerza y de armas de fuego por los funcionarios encargados de hacer cumplir la ley", en: Criminalia, Año LXXIV, No. 1, eneroabril, Academia Mexicana de Ciencias Penales, Editorial Porrúa, México, 2008.

GUERRERO AGRIPINO, Luis Felipe, La delincuencia organizada. Algunos aspectos penales, criminológicos político-criminales, Universidad de Guanajuato, Facultad de Derecho, México, 2001.

a) "Panorama general de la criminalidad grupal en México. Desarrollo de la delincuencia organizada y otras manifestaciones de alto impacto", en: Iustel, número 15, España, 2011.

b) Seguridad pública y prevención del delito en el estado social de derecho. Especial comentario a la trascendencia de la educación, Guanajuato, Universidad de Guanajuato, 2007.

c) "Delincuencia organizada: una amenaza emergente para el Estado mexicano", en: Letras Jurídicas, número 12, España, 2011.

d) "La prevención desde fuera del sistema penal. Tendencias actuales del estado mexicano", en: Revista General de Derecho Penal No. 19, Salamanca, 2013.

IBARRA PALAFOX, Francisco, "El Leviatán encadenado o la legitimidad de la violencia estatal”, en: MEDINA MORA ICAZA, Eduardo, coordinador, Uso Legítimo de la fuerza, México, Instituto Nacional de Ciencias Penales, 2008. 
INSTITUTO CIUDADANO DE ESTUDIOS SOBRE LA INSEGURIDAD (ICESI), Propuesta para la aplicación legítima de la fuerza por parte de la policía. México, 2007, disponible en: www.icesi.org.mx.

INSTITUTO PARA LA SEGURIDAD Y LA DEMOCRACIA, A.C. (INSYDE), Policía y uso de la fuerza, una agenda clave de nuestra democracia, Cuaderno de Trabajo No. 16, 30 de noviembre de 2006.

"Políticas y protocolos institucionales para el uso de la fuerza", México, Centro de Certificación Profesional de Agencias Policiales, 2008, disponible en: www.insyde.org.mx

KALA, Julio César, "Las políticas de seguridad, en busca de un modelo policía", en: La Policía de Proximidad o Policía Comunitaria, México, (Sin más referencias bibliográficas).

MARTÍNEZ LUNA, Antonio. "El uso de la Fuerza Público”, en: MEDINA MORA ICAZA, Eduardo, Coordinador, Uso Legítimo de la Fuerza, México, Instituto Nacional de Ciencias Penales, 2008.

NÚÑEZ PEDRAZA, Manuel. "La Policía en la Prevención del Delito” en: CARRANZA Elías (Coordinador), Delito y seguridad de los habitantes, Unión Europea, Siglo XXI editores, 1997.

PEÑALOZA, Pedro José, Notas graves y agudas de la seguridad pública, México, Instituto Nacional de Ciencias Penales, 2003.

PEREZ CANCHOLA, José Luis, "La seguridad pública y la profesionalización del personal policial en la administración pública actual” en: Seguridad Pública Nacional en México y en Francia. Memoria coloquio franco-mexicano sobre seguridad pública nacional, México, Secretaría de Gobernación, Embajada de Francia e Instituto Nacional de Administración, 1998.

PROCURADURÍA DE LOS DERECHOS HUMANOS DEL ESTADO DE GUANAJUATO Y SECRETARÍA DE SEGURIDAD PÚBLICA DEL ESTADO DE GUANAJUATO, Seguridad Pública y Derechos Humanos... La Seguridad Pública como garantía de los Derechos Humanos, México, 2008.

REGINO, Gabriel. “Seguridad pública en México. Una Aproximación al holocausto”, en: Derecho Penal Online. Revista electrónica de doctrina y jurisprudencia en línea, consultado en junio 2009, disponible en: hppt://www.derechopenalonline.com

SANCHEZ SANDOVAL, Augusto, Derechos Humanos, Seguridad Pública y Seguridad Nacional, México, Instituto Nacional de Ciencias Penales, 2000.

SECRETARÍA DE SEGURIDAD PÚBLICA FEDERAL, Modelo Policial, Gobierno Federal, México, septiembre, 2008.

SECRETARIADO EJECUTIVO DEL SISTEMA NACIONAL DE SEGURIDAD PÚBLICA, Programa Rector de Profesionalización, México D.F., Secretaría de Gobierno Federal, 2010.

SISTEMA INTEGRAL DE DESARROLLO POLICIAL, México D.F., Secretaría de Seguridad Pública Federal, 2010. 
SWATMADRID, "Medios no letales en el uso policial de la fuerza", disponible en: $\underline{w w w}$. swatmadrid.com

VILLALOBOS, Joaquín, "El Estado y el uso responsable de la fuerza" en: MEDINA MORA ICAZA, Eduardo, coordinador, Uso Legítimo de la Fuerza, México, Instituto Nacional de Ciencias Penales, 2008.

VITALE, Ermanno, "Democracia, derechos y uso de la fuerza pública", en: INSTITUTO NACIONAL DE CIENCIAS PENALES. El uso de la fuerza pública en un Estado democrático de Derecho, Memoria del Congreso Internacional celebrado en agosto de 2010, México, 2011.

YAÑEZ ROMERO, José Arturo. "Comentario al Artículo 8” en: Ley que Regula el Uso de la Fuerza de los cuerpos de seguridad pública del Distrito Federal, comentada, México, Colección de estudios Legislativos, Dirección de Investigación del Instituto de Formación Profesional, 2008.

FUENTES LEGISLATIVAS

Constitución Política de los Estados Unidos Mexicanos

Dictamen de la Comisión de Seguridad Pública, con proyecto de decreto que expide la Ley General del Sistema Nacional de Seguridad Pública, en la Gaceta Parlamentaria de la Cámara de Diputados, número 2648-IV, jueves 4 de diciembre de 2008.

Ley General del Sistema Nacional de Seguridad Pública

Ley que regula el uso de la fuerza de los cuerpos de seguridad pública del Distrito Federal, 22 de abril de 2008, GO, disponible en la página electrónica de la Asamblea Legislativa del DF en: www.asambleadf.gob.mx

Proyecto de decreto que crea la Ley General de Procedimientos Policiales y Uso Legítimo de la Fuerza Pública, disponible en la página electrónica del Senado de la República en www.senado.gob.mx

Recomendación general no. 12/2006 sobre el uso ilegítimo de la fuerza y de las armas de fuego por los funcionarios o servidores públicos encargados de hacer cumplir la ley, emitida por la CNDH el 12 de febrero de 2006, disponible en: http://www.ordenjuridico.gob. $\mathrm{mx} /$ Federal/OA/CNDH/Recomendaciones/14022006\%282\%29.pdf

FUENTES ELECTRÓNICAS

AMNISTÍA INTERNACIONAL, El estado de los derechos humanos en el mundo. Informe 2010, disponible en: http://thereport.amnesty.org/sites/default/files/AIR2010_AZ_ ES.pdf\#page $=212$

Periódico La Jornada, edición electrónica disponible en www.jornada.unam.mx Procuraduría General de la República, sala de prensa, disponible en el sitio electrónico, http:// 
www.pgr.gob.mx/prensa/2007/bol10/Ago/b98510a.shtm Senado de la República, sitio electrónico disponible en www.senado.gob.mx 
